\title{
Etnomatematika pada Makanan Tradisional Melayu Daik Lingga Sebagai Sumber Belajar
}

\author{
Maghfiroh Sa Adatul Muk Minah ${ }^{1)}$, Nur Izzati ${ }^{2)}$ \\ Universitas Maritim Raja Ali Haji \\ 1)170384202048@student.umrah.ac.id \\ 2) nurizzati@umrah.ac.id
}

\begin{abstract}
The purpose of this study was to find mathematical activities in the Daik Lingga culture. This research focuses on the ethnomatematic exploration of the traditional Malay food of Daik Lingga which can be used as a source of learning mathematics. Daik's traditional food is generally made from sago. This research is a qualitative type and uses an ethnographic approach. The data collection technique was carried out by interviewing related sources and documentation. The data analysis technique was based on the design of Miles and Huberman by reducing data, presenting data, and concluding/ verification. Based on the results of data collection, there are several mathematical elements in the traditional Malay food of Daik Lingga. The mathematical elements contained include shapes (circles and right triangles), space shapes (cones), folding symmetry, reflection, rotation, acute angles, right angles, and parallel lines. Therefore, Daik Lingga's traditional food can be used as a source of interesting mathematics learning for students so that learning becomes meaningful.
\end{abstract}

Keywords : Ethnomatematics, Elements of mathematics, Traditional food

This is an open access article distributed under the Creative Commons 4.0 Attribution License, which permits unrestricted use, distribution, and reproduction in any medium, provided the original work is properly cited. $₫ 2018$ by author and Universitas Negeri Padang.

\section{PENDAHULUAN}

Undang-Undang Republik Indonesia No mor 20 Tahun 2003 tentang Sistem Pendidikan Nasional Bab X Kurikulum Pasal 37 menyatakan bahwa matematika merupakan mata pelajaran wa jib untuk sekolah dasar dan sekolah menengah. Lampiran Peraturan Menteri Pendidikan dan Ke budayaan Nomor 22 Tahun 2016 tentang Standar Proses Pendidikan Dasar Dan Menengah menya takan proses pembelajaran pada satuan pendi dikan diselenggarakan secara interaktif, inspira tif, menyenangkan, menantang, memotivasi pe serta didik untuk berpartisipasi aktif, serta mem berikan ruang yang cukup bagi prakarsa, krea tivitas, dan kemandirian sesuai dengan bakat, minat, dan perkembangan fisik serta psikologis peserta didik.

Pada pembelajaran matematika, masih ba nyak dijumpai kegiatan aktivitas pembelajaran yang mengakibatkan tidak terlihatnya keaktivan peserta didik, menjenuhkan, dan tidak memberi kan kebermaknaan dan pengalaman yang konkrit dari pembelajaran yang dilaksanakan (Richardo, 2017). Menurut Abdullah (2017) sifat matema tika banyak digunakan dalam kehidupan seharihari. Keadaan tersebut semestinya bisa memper mudah peserta didik untuk memahami matema tika. Namun, kembali lagi kepada praktiknya, yai tu masih banyak pembelajaran matematika yang dilaksanakan tidak memakai atau menggunakan keadaan lingkungan sekitar. Sehingga peserta didik banyak merasa jenuh dan tidak memiliki kebermaknaan dalam pembelajaran matematika. Oleh karenanya dibutuhkan suatu sumber belajar kontekstual yang familiar dengan peserta didik. Hal tersebut dimaksudkan agar dapat mengaitkan pembelajaran matematika ke dalam kehidupan sehari-hari supaya pembelajaran matematika le bih menyenangkan, tidak menjenuhkan, dan pe serta didik mendapatkan pengalaman yang nyata. Van de Henvel_Panhuizel menegaskan, bila pe serta didik belajar matematika terpisah dengan pengalaman mereka sehari-hari, maka peserta di dik akan cepat lupa dan tidak dapat mengapli kasikan matematika sehingga mengakibatkan ke jenuhan. Selain itu, peserta didik perlu dilatih menerapkan kembali konsep matematika yang telah dimiliki peserta didik dalam kehidupan sehari-hari atau pada bidang lainnya (dalam Rahmawati, 2013).

Kebudayaan masyarakat setempat bisa dija dikan pembelajaran nyata dan sumber belajar ba gi peserta didik. Pembelajaran yang mengaitkan konsep matematis dengan kebudayaan masyara kat lokal dikenal dengan istilah etnomatematika. 
Etnomatematika ialah ilmu yang digunakan un tuk mengetahui bagaimana matematika diadapta si dari suatu budaya (Richardo, 2017). Etnoma tematika membedakan antara matematika yang ada di sekolah dengan matematika yang sudah ada di dalam budaya secara turun temurun yang terkadang jarang dijamah oleh sistem perseko lahan (Turmudi, 2017).

Istilah etnomatematika berasal dari kata ethnomathematics diperkenalkan oleh seorang matematikawan berasal dari Brasil yang bernama D'Ambrosio pada tahun 1977 (Huda, 2018). D'Ambrosio (2008) menyatakan kata awalan ethno mengacu pada kelompok kebudayaan yang dapat dikenali. Sebagai contoh, perkumpulan su $\mathrm{ku}$ di suatu negara dan kelas-kelas profesi dalam masyarakat termasuk pula bahasa dan kebiasaan mereka dalam kehidupan sehari-hari. Kemudian, mathema disini berarti mengerti, menjelaskan, dan mengelola hal-hal nyata secara spesifik dengan menghitung, mengurutkan, mengukur, mengklasifkasi, dan memodelkan suatu pola yang muncul pada suatu lingkungan. Akhiran tics memiliki arti yaitu seni dalam teknik. Secara istilah etnomatematika dapat diartikan sebagai matematika yang dipraktikkan pada kelompok budaya yang diidentifikasi seperti masyarakat nasional suku, kelompok buruh, anak-anak pada kelompok usia tertentu dan kelas profesional (Huda, 2018).

Rakhmawati (2016) mendefinisikan etno matematika sebagai metode khusus yang diguna kan oleh suatu kelompok budaya atau masyarakat tertentu terkait aktivitas matematika. Aktivitas matematika di sini maksudnya adalah aktivitas yang mengandung proses pengabstraksian dari pengalaman nyata di kehidupan sehari-hari ke dalam matematika ataupun sebaliknya. Model pembelajaran matematika yang menghubungkan konsep-konsep matematika dengan permasalah an dalam dunia nyata, salah satunya adalah model pembelajaran berbasis etnomatematika (Andriya ni, 2017). Lebih jauh Andriyani (2017) menjelas kan bahwa pembelajaran berbasis etnomatema tika selain dapat mempelajari matematika secara kontekstual, juga dapat memotivasi belajar pe serta didik untuk aktif di kelas, di mana peserta didik dapat memahami budaya dan sekaligus menumbuhkan nilai karakter.

Saat ini, sudah banyak penelitian-peneli tian di bidang etnomatematika, bahkan mencakup berbagai aspek kehidupan. Salah satu aspek kehi dupan yang bisa diangkat ke dalam bidang etno matematika adalah makanan tradisional. Bebera pa penelitian yang mengangkat tentang unsur ma tematis dalam makanan tradisional diantaranya: etnomatematika makanan tradisional daerah $\mathrm{Bu}$ gis sebagai sumber belajar matematika (Pathud din, 2019) dan etnomatematika pada bentuk ja janan pasar di Daerah Istimewa Yogyakarta (Hu da, 2018). Konsep matematika yang ditemukan dalam penelitian-penelitian tersebut ditemukan pada makanan tradisional dari daerah masingmasing peneliti yakni Bugis dan Daerah Istimewa Yogyakarta. Untuk daerah Daik Lingga, masih belum ada pembelajaran matematika yang meng gunakan isu-isu budaya lokal atau etnomate matika sebagai sumber belajar. Melalui fakta tersebut, maka peneliti ingin mengangkat isu budaya lokal itu terkhusus makanan tradisional Daik Lingga untuk dijadikan sumber belajar melalui kajian etnomatematika. Adapun perbeda annya dengan penelitian ini adalah penemuan konsep matematika melalui identifikasi etnoma tematika pada makanan tradisional melayu Daik Lingga yang dapat dijadikan sumber belajar.

Daik Lingga merupakan salah satu kabu paten di Provinsi Kepulauan Riau yang dijuluki sebagai Bunda Tanah Melayu. Daik Lingga meru pakan Pusat Pemerintahan Kebesaran Kesultanan Lingga pada tahun 1878 hingga 1900. Masyara kat Daik Lingga sangat menjunjung tinggi kebu dayaan dan warisan leluhur mereka salah satunya dengan aktif dalam pembuatan makanan tradi sional. Makanan tradisional Daik Lingga bahkan sudah ada beberapa yang masuk dalam penca tatan warisan budaya tidak benda (WBTB). Bila ditelusuri lebih jauh baik dari bentuk dan proses pembuatan makanan tradisional Daik Lingga ter dapat banyak konsep matematika yang dapat dijadikan sumber belajar. Hal inilah yang menja di motivasi bagi penulis untuk mengidentifikasi etnomatematika pada makanan tradisional mela yu Daik Lingga sebagai sumber belajar.

\section{METODE PENELITIAN}

Jenis penelitian ini adalah penelitian kuali tatif dengan pendekatan etnografi. Etnografi ada lah uraian dan penafsiran suatu budaya atau sis tem kelompok sosial, peneliti menguji kelompok tersebut dan mempelajari pola perilaku, kebia saan, dan cara hidup (Rahmat, 2009). Adapun sub jek penelitian atau sumber data yang dipilih ada lah anggota Lembaga Adat Melayu yang dalam hal ini Bapak Lazuardi dan masyarakat yang biasa memasak makanan tradisional tersebut. 
Dalam mengeksplorasi etnomatematika pa da makanan tradisional Daik Lingga, peneliti me lakukan beberapa tahapan penelitian. Adapun tahapannya, yaitu: menentukan sumber data, me lakukan wawancara, melakukan dokumentasi, mereduksi data, melakukan penyajian data, dan penarikan kesimpulan dan membuat laporan hasil penelitian dalam bentuk artikel. Wawancara se mi-terstruktur dilakukan terhadap narasumber dan studi dokumen dilakukan guna memperoleh data yang valid mengenai makanan tradisional Melayu Daik Lingga.

Sejalan dengan teknik pengumpulan data di atas, maka dalam penelitian ini peneliti meng gunakan instrumen lembar wawancara dan pene liti sendiri sebagai instrumen utamanya. Adapun indikator-indikator dari lembar wawancara disaji kan dalam Tabel 1.

Tabel 1. Indikator lembar wawancara

\begin{tabular}{|c|l|}
\hline No. & \multicolumn{1}{|c|}{ Indikator } \\
\hline 1. & $\begin{array}{l}\text { Sejarah makanan tradisional Daik } \\
\text { Lingga }\end{array}$ \\
\hline 2. & $\begin{array}{l}\text { Jenis makanan tradisional Daik } \\
\text { Lingga }\end{array}$ \\
\hline 3. & $\begin{array}{l}\text { Bentuk dan makna makanan } \\
\text { tradisional Daik Lingga }\end{array}$ \\
\hline 4. & $\begin{array}{l}\text { Aspek geometri pada makanan } \\
\text { tradisional Daik Lingga }\end{array}$ \\
\hline
\end{tabular}

Jenis data yang diperoleh dalam penelitian ini adalah data kualitatif. Data dinyatakan valid jika narasumber menjawab dengan didasari pan duan beberapa arsip dan dibuktikan dengan me nunjukkan secara langsung terkait makanan tra disional Daik Lingga. Selanjutnya, setelah menda patkan data dilakukan analisis data untuk melihat unsur matematika yang terkandung dalam ma kanan tradisional Daik Lingga tersebut. Teknik analisis data mengacu pada Miles dan Huberman tahun 1992, yaitu dengan mereduksi data, penya jian data, serta kesimpulan/verifikasi (Sugiyono 2014).

Reduksi data di sini adalah menggolong kan, membuang yang tidak perlu, dan mengorga nisasikan data dengan cara sedemikian rupa sam pai berbagai kesimpulan finalnya dapat ditarik dan diverifikasi. Penyajian data merupakan aktivi tas menggabungkan informasi yang tersusun da lam suatu bentuk yang padu. Setelah itu baru da pat ditarik kesimpulan secara utuh.

| Volume 5| Nomor 1|Mei 2021|Page 1-7

\section{HASIL DAN PEMBAHASAN}

\section{Makanan Tradisional Melayu Daik Lingga}

Berdasarkan hasil wawancara pada bebera pa narasumber, makanan tradisional melayu Daik Lingga sebagian besar berbahan utama sagu. Hal ini dimulai ketika Sultan Mahmud Riayat Syah (1761-1812) memindahkan pusat kerajaan pada 24 Juli 1787 dari Hulu Riau ke Daik Lingga maka sagu merupakan makanan pokok yang dibutuh kan. Kemudian dikembangkan oleh Sultan Sulai man Badrul Alam Syah II (1857-1883) guna ke majuan perekonomian masyarakat.

Hasil pengumpulan data penelitian didapat kan beberapa jenis makanan tradisional melayu Daik Lingga. Menurut keterangan bapak Lazuar di selaku narasumber, makanan tradisional mela yu Daik Lingga ini bisa dikelompokkan menjadi tiga yaitu makanan berat, makanan setengah be rat, dan makanan ringan. Makanan berat dianta ranya sagu lempeng, lempeng belaok, gubal, ke purun, lakse, dan bubur lambok serta nasi be sar/nasi sekone. Makanan setengah berat dianta ranya adalah nasi dagang dan nasi sepinggan. Sedangkan makanan ringan diantaranya kueh mueh pengantin (kue khasidah, kue rumput surge, kue pasir neraka, kue telur belangkas, kue tahi burung, kue anta kesukma, kue kacau tepung, kue ganti susu, kue sango atau agar-agar, kue panganan bakar, kue bahulu berendam, dan kue telur laba-laba), keripik sagu lenggang, sagu lemak, keripik cincin, keripik sagu bakar, dan kue apam. Ada yang unik dari makanan-makanan tradisional ini, yaitu istilah "kepunan". Pantang orang tidak menyicip makanan-makanan yang sudah terhidang terutama yang terbuat dari sagu. Masyarakat percaya bahwa akan adanya hal bur uk yang akan terjadi jika tidak menyicipi ma kanan tersebut. Tapi pada dasarnya itu merupa kan suatu bentuk penghargaan terhadap makanan dan orang yang sudah memasak. Karena proses dari penggilingan sagu hingga jadi makanan itu tidak singkat.

\section{Eksplorasi Etnomatematika pada Bentuk Makanan Tradisional Melayu Daik Lingga \\ Eksplorasi makanan tradisional melayu} Daik Lingga terbagi menjadi beberapa kompo nen, yaitu bentuk makanan, corak pada makanan, dan komposisi pembuatan makanan. Pada pene litian ini, peneliti fokus pada eksplorasi bentuk dan corak pada makanan ringannya. Makanan 
tradisional melayu Daik Lingga mengandung un sur matematika diantaranya keripik sagu leng gang dan keripik cincin. Sedangkan makanan ringan yang memuat unsur corak yaitu kue kha sidah, kue ganti susu, kue kacau tepung dan kue sango. Keempatnya merupakan bagian dari kueh mueh pengantin orang Melayu Daik Lingga. Oleh karena itu, eksplorasi etnomatematika ha nya dilakukan pada keripik sagu lenggang, keri pik cincin, kue khasidah, kue ganti susu, kue ka cau tepung, dan kue sango.

\section{a. Keripik Sagu Lenggang}

Keripik sagu lenggang merupakan ma kanan yang terbuat dari butiran sagu lenggang yang dicampur dengan gula merah kemudian digoreng. Berdasarkan wawancara dengan $\mathrm{Bu}$ Ipah, untuk membentuk keripik sagu lenggang tersebut menggunakan cetakan kaleng susu bekas yang berukuran sedang dengan bentuk lingkaran berdiameter 4 inci. Sehingga keripik sagu leng gang ini memiliki bentuk lingkaran penuh. Terlihat dengan jelas pada Gambar 1 bahwa keripik sagu lenggang memuat konsep lingkaran. Karena sesuai dengan pengertian lingkaran, yaitu kumpulan titik-titik pada garis lengkung yang mempunyai jarak yang sama terhadap pusat lingkaran.

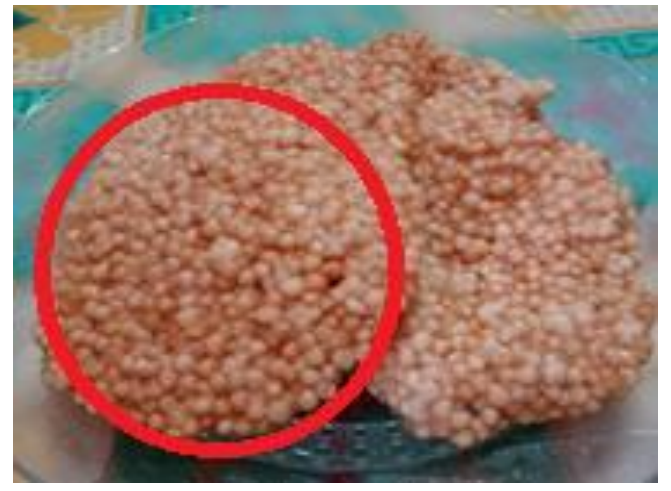

Gambar 1. Bangun datar lingkaran pada keripik sagu lenggang

\section{b. Keripik Cincin}
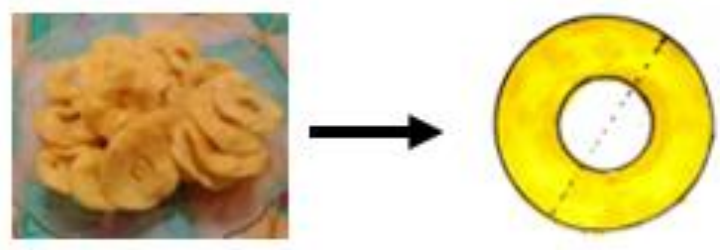

Gambar 2. Bangun datar lingkaran pada keripik cincin
Keripik cincin adalah makanan tadisional Daik Lingga yang juga terbuat dari sagu. Sama halnya dengan keripik sagu lenggang, keripik cincin memiliki bentuk lingkaran namun di tengahnya berlubang dengan bentuk lingkaran juga. Lingkaran besar memiliki diameter $3,5 \mathrm{~cm}$, sedangkan lingkaran bagian dalamnya memiliki diameter $1,5 \mathrm{~cm}$. Sehingga membentuk seperti cincin. Konsep yang terkandung dalam keripik cincin ini adalah konsep lingkaran dan konsep luas yang diarsir.

Luas lingkaran yang diarsir adalah luas lingkaran besar dikurangi luas lingkaran kecil. Rumus luas lingkaran adalah $\pi r^{2}$. ra sebagai jarijari jari-jari lingkaran besar dan rb sebagai jarijari lingkaran kecil. Sehingga luas daerah yang diarsir adalah $\pi\left(r_{a}^{2}-r_{b}^{2}\right)$.

\section{c. Kue Khasidah}
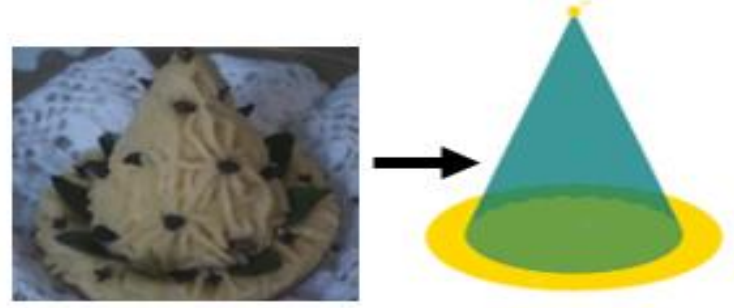

\section{Gambar 3. Lingkaran dan kerucut pada kue khasidah}

Makna yang terkandung dalam kue kha sidah ini adalah "Keutuhan yang harus dihargai dengan penuh tanggung jawab". Setelah kue ini dimakan maka pengantin harus membayar sejum lah uang tebusan seikhlasnya dengan niat mengha diahkan pada mak inang pengantin. Kue khasidah memiliki bentuk yang kerucut dan lingkaran di bawahnya. Sesuai dengan pengertian kerucut yai tu bangun tiga dimensi yang dibatasi oleh suatu sisi lengkung dan sisi alas berbentuk lingkaran.

\section{d. Kue Ganti susu}

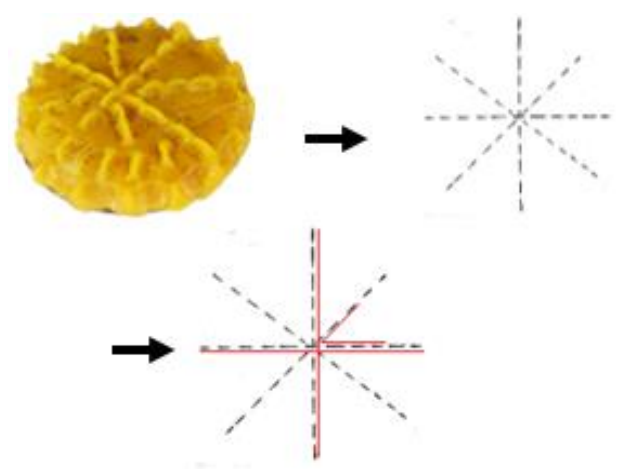

Gambar 5. Konsep refleksi, simetri lipat, dan sudut lancip pada kue ganti susu 
Bentuk dari kue ganti susu ini merupakan lingkaran dengan bergerigi di samping-samping nya. Sedangkan coraknya dibuat dengan mem buat dua garis putus-putus di tengah terlebih dahu lu sehingga membentuk tanda tambah kemudian di sela-selanya juga dibuat garis putus-putus yang sama. Konsep yang terkandung dalam corak kue ganti susu adalah konsep refleksi, simetri lipat, dan sudut lancip.

\section{e. Kue kacau tepung}

Kue kacau tepung tidak jauh berbeda de ngan kue ganti susu. Bentuknya lingkaran dan memiliki corak yang saling simetris. Dalam co rak kue kacau tepung terdapat konsep refleksi, simetri lipat, garis sejajar, dan sudut lancip. Beri kut gambarnya.

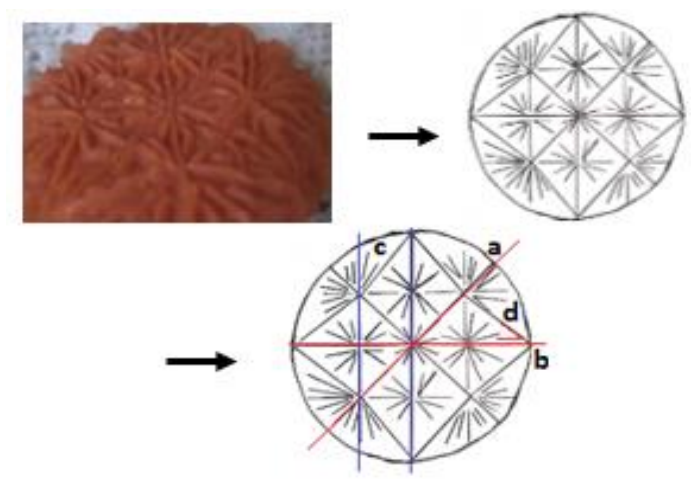

Gambar 6. Konsep (a) refleksi, (b) simetri lipat, (c) garis sejajar, dan (d) sudut lancip

\section{f. Kue sango}

Kue sango atau agar-agar ini berbentuk bunga dan 2 helai daun. Konsep matematika yang terdapat dalam kue ini adalah konsep refleksi pada bentuk bunganya dan rotasi pada helai daunnya.

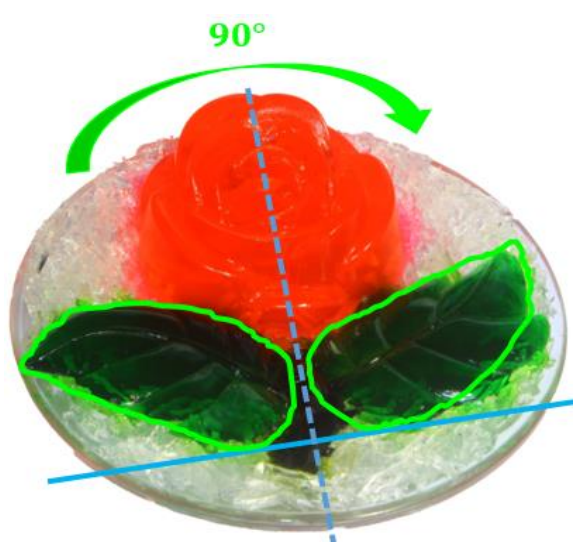

Gambar 7. Konsep refleksi dan rotasi pada kue sango

| Volume 5| Nomor 1|Mei 2021|Page 1-7
Pada bentuk bunganya dibuat seperti bunga ros yang bila dipotong sama besar akan terlihat se perti pencerminan. Sedangkan kedua helai daun dicetak menggunakan satu cetakan daun, namun saat peletakan helai yang kedua diletakkan de ngan memutarnya tepat $90^{\circ}$ dari peletakan per tama.

Berdasarkan hasil penelitian pada keenam makanan tersebut, ditemukan praktik matematis yaitu bidang datar yang meliputi konsep segitiga siku-siku, lingkaran dan luas lingkaran, bangun ruang yang meliputi konsep kerucut, geometri (konsep refleksi dan rotasi), simetri lipat, garis sejajar, dan konsep sudut lancip, apabila ditinjau dari bentuk makanan serta corak pada makanan nya. Pada dasarnya, konsep matematika yang dijumpai pada bentuk makanan tersebut tentu tanpa disadari secara langsung oleh orang yang membuat atau memasak makanan tersebut. Selan jutnya, konsep serta bentuk dan corak makanan yang menginterpretasikan konsep tersebut dirang kum dalam Tabel 2 di bawah.

Tabel 2. Konsep matematika pada bentuk dan corak makanan tradisional Daik Lingga

\begin{tabular}{|c|c|c|}
\hline No & $\begin{array}{c}\text { Konsep } \\
\text { matemati } \\
\text { ka }\end{array}$ & Bentuk \\
\hline 1 & Lingkaran & \\
\hline 2 & Kerucut & \\
\hline 3 & $\begin{array}{l}\text { Refleksi } \\
\text { dan } \\
\text { simetri } \\
\text { lipat }\end{array}$ & \\
\hline 4 & $\begin{array}{l}\text { Sudut } 90^{\circ} \text {, } \\
\text { dan sudut } \\
\text { lancip, } \\
\text { serta garis } \\
\text { sejajar }\end{array}$ & \\
\hline 5 & $\begin{array}{l}\text { Refleksi } \\
\text { dan Rotasi }\end{array}$ & \\
\hline
\end{tabular}




\section{Etnomatematika pada Makanan Tradisional Melayu Daik Lingga Sebagai Sumber Belajar}

Jika ditinjau dari bentuk makanannya, kita bisa menggunakan konteks berupa bentuk ling karan dengan makanan tradisional Daik lingga yang berbeda-beda. Misal kita bisa mencontoh kan konsep lingkaran yakni himpunan titik-titik yang berjarak sama terhadap suatu titik dengan keripik sagu lenggang. Oleh karena itu, konsepkonsep yang terdapat pada makanan tradisional melayu Daik Lingga tersebut dapat menjadi sumber belajar kontekstual pada pembelajaran matematika.

Pendidik dapat membuat suatu bahan ajar berupa modul atau lembar kerja peserta didik dengan konteks makanan tradisional Daik Lingga untuk sumber belajar peserta didik. Pendidik juga dapat memberikan tugas kepada peserta didik un tuk mengamati secara langsung makanan tradisio nal Melayu Daik Lingga. Pada modul, pendidik dapat memberikan suatu pancingan pertanyaan matematika yang berkaitan dengan makanan tra disional tersebut untuk menemukan konsep mate matika. Di dalam modul tentu memuat soal-soal latihan, begitu juga pada lembar kerja peserta di dik. Soal-soal latihan tersebut dapat dikembang kan menggunakan konteks etnomatematika pada makanan tradisional Melayu Daik Lingga, seperti dalam memberikan pemahaman tentang konsep refleksi, simetri lipat, sudut, bangun datar berupa lingkaran.

Melalui modul atau LKPD etnomatemati ka sebagai sumber belajar yang langsung berkait an dengan lingkungan kehidupan peserta didik yakni makanan tradisional Melayu Daik Lingga, dipercaya mampu meningkatkan minat belajar pe serta didik yang kemudian memberikan keber maknaan belajar.

\section{KESIMPULAN}

Berdasarkan bentuk dan corak keenam ma kanan tradisional melayu Daik Lingga tersebut terdapat konsep-konsep matematika. Konsep yang terkandung yaitu lingkaran, kerucut, sudut siku-siku dan sudut lancip, garis sejajar, simetri lipat, refleksi dan rotasi. Oleh karena itu, pendidik dapat menggunakan hal-hal tersebut untuk membuat modul per-subbab sebagai sum ber belajar matematika serta menggunakan soalsoal latihan pada modul yang dikembangkan dengan konteks etnomatematika. Sehingga pem belajaran terasa lebih konkret, tidak membosan kan serta mengesankan bagi peserta didik. Pada akhirnya peserta didik akan mengerti kebergu naan dari pembelajaran matematika dalam kehi dupan sehari-hari di lingkungannya.

\section{DAFTAR PUSTAKA}

Abdullah, A.S. (2017). Ethnomathematics In Per spective Of Sundanese Culture. Journal on Mathematics Education Volume 8, No. 1, pp. 1-16 http://dx.doi.org/10.22342/jme.8. 1.3877.1-15

Andriyani. (2017). Etnomatematika: Model Baru dalam Pembelajaran. Jurnal Gantang.

D'Ambrosio, U dan Rosa, M. (2008). A. dialogue with ubiratan D'Ambrosio: a Brazilian conversation about ethnomathematics. Re vista Latinoamericana de Etnomatematica, Vol I No.2. 88-110.

Depdiknas. (2003). Undang-Undang Republik Indonesia Nomor 20 Tahun 2003 Tentang Sistem Pendidikan Nasional. Jakarta: Dep diknas

Huda, N. T. (2018). Etnomatematika Pada Ben tuk Jajanan Pasar di Daerah Istimewa Yog yakarta. Jurnal Nasional Pendidikan Mate matika Vol. 2, No. 2, Hal.217. http://dx. doi.org/10.33603/jnpm.v2i2.870

Kemendikbud. (2016). Salinan Lampiran Pera turan Menteri Pendidikan Dan Kebuda yaan Nomor 22 Tahun 2016 Tentang Standar Proses Pendidikan Dasar Dan Menengah. PERMENDIKBUD. https:// doi.org/https://doi.org/10.3929/ethz-b000238666

Lembaga Adat Melayu Kepulauan Riau. (2018). Kueh-Mueh Pengantin Tradisional Bunda Tanah Melayu. Daik: Lembaga Adat Mela yu Kepulauan Riau Kabupaten Lingga.

Pathuddin, H., Raehana, S. (2019). Etnomatemati ka: Makanan Tradisional Bugis Sebagai Sumber Belajar Matematika. Jurnal Mate matika dan Pembelajaran Volume 7, No 2, (307-327). https://doi.org/10.24252/mapa n.2019v7n2a10

Rahmat, P. S. (2009). Penelitian Kualitatif. Equilibrium, 5(9). 1-8. http://yusuf.staff. ub.ac.id

Rahmawati, F. (2013). Pengaruh Pendekatan Pen didikan Realistik Matematika dalam Me ningkatkan Kemampuan Komunikasi Ma tematis Siswa Sekolah Dasar. Kumpulan 
Makalah Seminar Semirata 2013. 225238. https://jurnal.fmipa.unila.ac.id

Rakhmawati, R. (2016). Aktivitas matematika berbasis budaya pada masyarakat Lam pung. Al Jabar: Jurnal Pendidikan Mate matika, 7(2), 221-230. https://doi.org/doi. org/10.24042/ajpm.v7i2.37

Richardo, R. (2017). Peran Ethnomatematika dalam Penerapan Pembelajaran Matemati ka Pada Kurikulum 2013. LITERASI (Jur nal Ilmu Pendidikan). https://doi.org/10. 21927/literasi.2016.7(2).118-125

Sugiyono. (2014). Memahami penelitian kualita tif $(x)$. Bandung: cv. Alfabeta Bandung.

Turmudi. (2017). Ethnomathematics: Apa menga pa dan bagaimana implementasi dalam pembelajaran matematika di kelas. Semi nar Nasional Matematika dan Pendidikan Matematika (2nd SENATIK) (pp. 1-9). http://prosiding.upgris.ac.id/index.php/sen _2017/sen_2017/paper/view/1625/1580. 